\title{
Meta-Analysis of Scientific Papers in the Field of Motor Skills from Volleyball Published in the Journal Sport Mont 2006-2016
}

\author{
Gorica Zoric ${ }^{1}$ \\ 'University of Montenegro, Faculty for Sport and Physical Education, Niksic, Montenegro
}

\begin{abstract}
The main goal of this research was to determine one meta analysis of published original scientific papers in the area of motor abilities in volleyball in Sport Mont Journal in 2006-2016. From the review of the published original scientific papers that are being analyzed, it can be seen that this is a longitudinal research. In this paper, a meta analysis of 6 papers in the field of motor skills in volleyball was conducted.

Analyzing the basic central and dispersion parameters in all original scientific papers in the final state, it was noticeable that the arithmetic meanings had better values in almost all values compared to the initial state. To determine the statistical significance for evaluating different tests in published works, $t$-test for dependent samples and multivariate analysis of MANOVA were applied. T-test values and multivariate analyzes were significant or significance level (Sig.) from 0.01 ( $p \leq .01)$ in almost all variables. This systematic overview shows a comparative analysis of the collected studies and the processed data. It can be concluded that the training program of all scientific orginal papers has led to positive transformations.
\end{abstract}

Key words: Meta-Analysis, Sport Mont, Motor Skills, Volleyball

\section{Uvod}

Sport Mont je časopis u kojem se objavljuju originalni recenzirani naučni članci i interdisciplinarni prikazi istraživanja iz oblasti sportske nauke, čiji su autori naučnici iz cijelog svijeta. Početak publikovanja bio je za uredništvo veoma težak, ali iz godine u godinu situacija se mijenjala, radovi koji su objavljivani bili su sve kvalitetniji, pa se može reći da je časopis "Sport Mont" dospio do visokog nivoa u svijetu nauke. Svrha časopisa je promocija nauke i istraživanja, sa posebnom pažnjom posvećenom sportskoj nauci širom Crne Gore i izvan nje. Ova meta-analiza daje pregled objavljenih orginalnih naučnih radova iz oblasti odbojke u časopisu "Sport Mont". Analizirani su radovi objavljeni od 2006. do 2016. godine.

Odbojka je polistrukturalna, aciklična kompleksna aktivnost, kolektivna sportska igra koja pred igrače postavlja brojne zahtjeve definisane pravilima i strukturom igre. Kroz fazu organizacije odbrane i napada dolazi do razmjene poena koje karakterišu visoko-intenzivne aktivnosti uz periode kratkotrajnog odmora. Smatra se anaerobnim sportom sa metaboličkim zahtjevima za energijom zadovoljenim dominantno fosfokreatinskim sistemom (Kunstlinger et al., 1987). Da bi postigao visok nivo izvođenja, od igrača se zahtjeva ne samo usavršavanje tehničko-taktičkog umjeća već i ispoljavanje visokog nivoa motoričkih sposobnosti eksplozivne snage, brzine i agilnosti. Dinamička snaga je dominantna u odbojci jer je ovaj sport struktuiran skokovima i brzim promjenama pravca kretanja. Uspjeh u odbojci svakako zavisi i od morfoloških karakteristika formiranog odbojkaša/ice, od kojih su osnovne tjelesna visina i masa, a koje se valorizuju s obzirom na trenutni uzrast odbojkaša/ica (Marelić i sar., 2008). Kako u svakoj sportskoj aktivnosti, tako i u odbojci, nijedan tehnički element se ne može izvesti bez adekvatne motoričke sposobnosti i u punoj mjeri ispoljiti bez racionalne tehnike izvođenja kretanja.

Osnovni cilj ovog istraživanja je bio da se sprovede meta

Correspondence:

Montenegro G.Zorić

Gport University of Montenegro, Faculty for Sport and Physical Education, Narodne omladine bb, 81400 Niksic, Montenegro E-mail: goricazoric27@gmail.com 
analiza objavljenih originalnih naučnih radova iz oblasti odbojke u časopisu "Sport Mont" od 2006. do 2016 godine.

\section{Metod}

Analiza sadržaja je metoda često prisutna u istraživanjima koja kvalitativno i kvantitativno sistematizuje objavljene radove na određenu temu, a u jednostavnijem obliku se koriste zbrajanje i deskripcija pomenutih radova. Jedinica analize sadržaja u ovom preglednom radu su naslovi originalnih naučnih istraživanja objavljenih u časopisu „Sport Mont“ od 2006 do 2016 godine. U ovom radu je sprovedena meta analiza i izdvojeno je 6 radova koji su klasifikovani po jednostavnom kriterijumu, a to je da se bave proučavanjem promjena motoričkih sposobnosti kod odbojkaša/ica. Bazične motoričke sposobnosti su sposobnosti koje ljudi već posjeduju, a specifične sposobnosti su stvorene i razvijene u specifičnim uslovima, što je najevidentnije kod sportista (Bjelica, Popović i Gardasevic, 2016b).

Program testiranja obuhvatao je uzorak od 240 učenika prvog razreda srednjih škola, uzrasta 15 godina \pm 6 mjeseci. Za procjenu ispitanika korišćeni su testovi za procijenu bazičko-motoričkih sposobnosti (koordinacija, brzina, fleksibilnost, i snaga) i tri testa za procjenu situaciono-motoričkih sposobnosti: odbijanje lopte prstima o zid za $30 \mathrm{sec}$, odbijanje lopte podlakticama o zid za $30 \mathrm{sec}$., i precizno serviranje preko mreže (Bećir, 2006). Program testiranja obuhatao je uzorak od 80 ispitanika, uzrasta od 15 do 18 godina. Za procjenu situaciono-motoričkih sposobnosti ispitanika korišćena su pet testova: japan test, jelka test, abalakovljev test, specifična spretnost - sscd i specifična spretnost - ssp (Bukvić, Huskić, i Aruković, 2008). Program testiranja obuhvatao je uzorak od 31 odbojkaša pionirskog uzrasta, a za procjenu ispitanika korišćeno je osam testova: japan test, sardžentov test, skok u dalj iz mesta, bacanje medicinke iz ležanja, podizanje trupa sa tla, sklekovi na tlu, taping rukom, i duboki pretklon na klupi (Karadžić, Doder, i Dokmanac, 2011). Program testiranja obuhvatao je uzorak od 54 ispitanika, uzrasta od 16 do 18 godina. Za procjenu bazično-motoričkih sposobnosti primjenjeno je 15 varijabla koje pripadaju pojedinim segmentima za mjerenje motoričkog prostora a oni se definišu kao mjere za procjenu segmentarne brzine, eksplozivne i repetativne snage, koordinacije i fleksibilnosti. Korišćena su sljedeći testovi: taping rukom, taping nogom, taping nogom o zid, pretklon na klupi, pretklon u sjedu raskoračno, čeona špaga, slalom rukama sa dvije lopte, koordinacija s palicom, koraci u stranu, ležanje- sjed, sklekovi, zakloni u ležanju i uspravljanju trupa, skok u vis iz mjesta, skok u vis iz zaleta i skok u dalj iz mjesta (Korjenić, i Jelčić, 2011). Program testiranja obuhvatao je uzorak od 45 ispitanika ( 25 djevojčica i 20 dječaka), uzrasta od 9 do 11 godina. Za procjenu ispitanika korišćena su četiri testa: skok udalj iz mesta za procenu gipkosti, duboki pretklon na klupi za brzinu alternativnih pokreta ruke, taping rukom za procenu agilnosti i test 9-3-6-3-9 (Batez, 2013). Program testiranja obuhvatao je uzorak od 120 odbojkašica, uzrasta 13 godina \pm 6 mjeseci, za procjenu ispitanika korišćeni su sledeći testovi: za procjenu osnovnih motoričkih vještina primijenjeno je devet testova: taping rukom, pretklon na klupi, rukovanje štapom, zaustavljanje, pritisak na šipke, podizanje tijela za 30 sekundi, tapkanje rukom, bacanje kugle od $1 \mathrm{~kg}$ iz lezećeg položaja, i bočni odbrambeni pokret; pet testova situacionih motornih vještina: preciznost taktičkog serviranja, uzastopni prolazi, zidni šiljci, Japan test i Jelka test (Mahmutović, Rađo, Talović, Lakota, Alić, i Jelešković, 2016).

$\mathrm{U}$ ovim objavljenim originalnim naučnim radovima, $\mathrm{u}$ segmentu komparativne statistike, za utvrđivanja razlika primijenjenih varijabli na inicijalnom i finalnom stanju, i kod kontrolnih i eksperimentalnih grupaa korišćene su diskriminativna parametrijska procedura Studentov T-test za zavisne uzorke i multivarijantna analiza varijanse MANOVA.

\section{Rezultati}

Za utvrđivanje statističke značajnosti (signifikantnosti) razlika aritmetičkih sredina (parcijalne kvantitativne promjene) varijabli za procjenu različitih testova u objavljenim radovima, primijenjen je T-test za zavisne uzorke i multivarijantna analiza MANOVA. Vrijednosti T-testa i multivarijantna analiza su bile na nivou značajnosti ili signifikantnosti (Sig.) od $0.01(\mathrm{p} \leq .01)$ u gotovo svim varijablama. Svi objavljeni origi-

Tabela 1. Studije koje su analizirale objavljene orginalne radove iz oblasi motoričke sposobnosti kod odbojkaša/ica

\begin{tabular}{|c|c|c|c|c|}
\hline Autor & $\begin{array}{c}\text { Cilj } \\
\text { istraživanja }\end{array}$ & $\begin{array}{c}\text { Uzorak/ } \\
\text { varijable }\end{array}$ & $\begin{array}{l}\text { Statist. } \\
\text { analiza }\end{array}$ & Rezultati \\
\hline $\begin{array}{l}\text { Bećir, } \\
\text { (2006) }\end{array}$ & $\begin{array}{l}\text { Utvrdi povezanost } \\
\text { između bazičo-motoričkih } \\
\text { sposobnosti i situaciono- } \\
\text { motoričkih informacija u } \\
\text { odbojci }\end{array}$ & $\begin{array}{l}240 \text { učenika/ } 12 \text { varijabli } \\
\text { bazičo-motoričkih sposobnosti } \\
\text { i } 3 \text { situaciono-motoričkih } \\
\text { informacija }\end{array}$ & T-test & $\begin{array}{l}\text { Utvrđene su statistički značajne } \\
\text { razlike u svim parovima varijabli, } \\
\text { na nivou } \\
\mathrm{p}<.01\end{array}$ \\
\hline $\begin{array}{l}\text { Bukvić i sar. } \\
(2008)\end{array}$ & $\begin{array}{l}\text { Utvrditi faktorsku (latentnu) } \\
\text { strukturu situaciono } \\
\text { motoričkih varijabli }\end{array}$ & $\begin{array}{l}80 \text { odbojkaša/ } 5 \text { varijabli za } \\
\text { procjenu situaciono-motoričkih } \\
\text { sposobnosti }\end{array}$ & T-test & $\begin{array}{l}\text { Utvrđene su statistički značajne } \\
\text { razlike u svim parovima varijabli, } \\
\text { na nivou } \\
\mathrm{p}<.01\end{array}$ \\
\hline $\begin{array}{l}\text { Karadžić i sar. } \\
\text { (2011) }\end{array}$ & $\begin{array}{l}\text { Utvrditi razlike između opšte } \\
\text { motoričke sposobnosti } \\
\text { mladih odbojkaša i } \\
\text { netreniranih dječaka istog } \\
\text { uzrasta }\end{array}$ & $\begin{array}{l}31 \text { dječaka ( } 16 \text { ekspirimentalna } \\
\text { i } 15 \text { konrolna grupa)/ } 8 \text { varijabli } \\
\text { za procjenu motoričkih } \\
\text { sposobnosti }\end{array}$ & T-test & $\begin{array}{l}\text { Statistički značajna razlika } \\
\text { utvrđena je samo u testu } \\
\text { podizanje trupa sa tla na nivou } \\
\mathrm{p}<.05\end{array}$ \\
\hline $\begin{array}{l}\text { Korjenić i sar. } \\
\text { (2011) }\end{array}$ & $\begin{array}{l}\text { Utvrditi procjenu } \\
\text { kvantitativnih i kvalitativnih } \\
\text { promjena motoričkih } \\
\text { sposobnosti pod uticajem } \\
\text { trenažnog programa }\end{array}$ & $\begin{array}{l}54 \text { ispitanika/15 varijabli za } \\
\text { procjenu bazično-motoričkih } \\
\text { sposobnosti }\end{array}$ & T-test & $\begin{array}{l}\text { Utvrđene su statistički značajne } \\
\text { razlike u svim parovima varijabli } \\
\text { između inicijalnog i finalnog } \\
\text { stanja, na nivou } \\
p<.00\end{array}$ \\
\hline
\end{tabular}


(continued from previous page)

\begin{tabular}{|c|c|c|c|c|}
\hline Autor & $\begin{array}{c}\text { Cilj } \\
\text { istraživanja }\end{array}$ & $\begin{array}{c}\text { Uzorak/ } \\
\text { varijable }\end{array}$ & $\begin{array}{l}\text { Statist. } \\
\text { analiza }\end{array}$ & Rezultati \\
\hline $\begin{array}{l}\text { Batez, } \\
\text { (2013) }\end{array}$ & $\begin{array}{l}\text { Utvrditi kvantitativne razlike } \\
\text { motoričkih sposobnosti djece } \\
\text { koja treniraju odbojku (9-11 } \\
\text { godina), u zavisnosti od pola }\end{array}$ & $\begin{array}{l}45 \text { djece ( } 25 \text { djevojčica i } 20 \\
\text { dječaka)/4 varijable za procenu } \\
\text { eksplozivne snage }\end{array}$ & MANOVA & $\begin{array}{l}\text { Utvrđeno je da postoji statističk } \\
\text { značajna razlika u cjelokupnom } \\
\text { sistemu analiziranih motoričkih } \\
\text { varijabli u zavisnosti od pola na } \\
\text { nivou } \\
p=.00\end{array}$ \\
\hline $\begin{array}{l}\text { Mahmutović i } \\
\text { sar. (2016) }\end{array}$ & $\begin{array}{l}\text { Nivo poboljšanja motoričkih } \\
\text { sposobnosti odbojkašica } \\
\text { pod uticajem kinezioloških } \\
\text { operatora }\end{array}$ & $\begin{array}{l}120 \text { odbojkašica/ } \\
9 \text { varijabli motoričkih vještina i } \\
5 \text { situacionih motornih vještina }\end{array}$ & T-test & $\begin{array}{l}\text { Utvrđene su značajne statističke } \\
\text { razlike u svim parovima varijabli } \\
\text { inicijalnog i finalnog stanja, na } \\
\text { nivou } \\
p<.01\end{array}$ \\
\hline
\end{tabular}

nalni naučni radovi su pokazali da postoje statistički značajne razlike kod gotovo svih varijabli, te se stoga može reći da je došlo do pozitivnih statistički značajnih parcijalnih efekata trenažnog programa, a vrijednosti T-testa i univarijantne i mulivarijantne analize (MANOVA) bile su značajne na nivou pouzdanosti. Iz pregleda svih ovih objavljenih originalnih naučnih radova koji se analiziraju, jasno je da je riječ o longitudinalnim istraživanjima sa ciljem da se utvrde promjene motoričkih sposobnosti kod odbojkaša/ica pod uticajem programiranog trenažnog rada. Riječ je o sledećim radovima: "Prediktorske vrijednosti bazično-motoričkih sposobnosti i relacije sa situaciono-motoričkim informacijama u odbojci kod 15-to godišnjaka”. (Bećir, 2006), Faktorska struktura situaciono-motoričkih varijabli odbojkaša-početnika”. (Bukvić, Huskić, \& Aruković, 2008), "Razlike u motoričkim sposobnostima odbojkaša i netreniranih učenika. (Karadžić, Doder, \& Dokmanac, 2011), "Transformacioni efekti bazično-motoričkih sposobnosti pod uticajem eksperimentalnog programa rada kod odbojkaša 16-18 godina. (Korjenić \& Jelčić, 2011). "Razlike u motoričkom status djece različitog pola u školi odbojke." (Batez, 2013), "Nivo transformacije motoričkih vještina odbojkašica pod uticajem trenera" (Mahmutović, Rađo, Talović, Lakota, Alić, \& Jelešković, 2016). Prikazan je i tabelaran pregled objavljenih radova (Tabela 1.)

\section{Diskusija}

U ovom radu je izvršena meta-analiza objavljenih originalnih naučnih radova iz oblasti procjene motoričkih sposobnosti odbojkaša/ica u odbojci. Iz pregleda svih objavljenih orginalnih naučnih radova koji su analizirani, vidi se da je riječ o longitudalnim istraživanjima, sa ciljem da se u vremenski dvije različite tačke utvrde promjene kod različitih varijabli, pod uticajem programiranog trenažnog rada.

Statistički značajne promjene su uočene kod svih varijabli. Najveći doprinos definisanju ovog faktora imaju testovi taping nogom i taping rukom. Analiza korespodentnih kanoničkih funkcija upućuje na pretpostavku da uspješno izvođenje specifičnih motoričkih kretnji u odbojci najviše zavisi od faktora frekvencija, obzirom da su sve projekcije ovog faktora visoke i u direktnoj korelaciji sa kanoničkom funkcijom (Bećir, 2006). Uočene su statistički značajne promjene kod svih varijabli (Bukvić, Huskić, \& Aruković, 2008). Na osnovu rezultata t-testa utvrđeno je da se dvije grupe ispitanika (trenirani mladi odbojkaši i njihovi netrenirani vršnjaci iz kontrolne grupe) uglavnom nisu statistički signifikantno razlikovali u pogledu opšte motoričkih sposobnosti. U čak sedam, od osam primenjenih opšte-motoričkih testova, nisu utvrđene značajne razli- ke na šta nedvosmisleno ukazuju veoma visoke vrijednosti realizovanog nivoa značajnosti (Sig.) koje su daleko prevazilazile teorijski limit od 0,05. Statistički značajna razlika utvrđena je samo u testu podizanje trupa sa tla kojim je hipotetski procenjivan repetitivni potencijal muskulature trbuha. Jedino je kod ovog testa, naime, realizovani nivo značajnosti bio ispod teorijskog limita (Sig <.05) (Karadžić, Doder, \& Dokmanac, 2011). Na osnovu rezultata značajnosti promjena (razlika) testiranih T- testom za zavisne uzorke, jasno je vidljivo da je primjenjeni trenažni program rada proizveo statistički značajne parcijalne kvantativne efekte u svim varijablama (Korjenić \& Jelčić, 2011). Primjenom postupka multivarijatne analize varijanse (MANOVA) utvrđeno je da postoji statistički značajna razlika u cjelokupnom sistemu analiziranih motoričkih varijabli u zavisnosti od pola na ispitivanom uzorku djece (Batez, 2013).

Analiza kvantitativnih promjena osnovnih motoričkih vještina pokazuje navažnije projekcije na odabranoj diskriminatornoj funkciji odbojkašica (Mahmutovic, Radjo, Talovic, Lakota, Alic, Jeleskovic, 2016).

Da podsjetimo, časopis “Sport Mont” u kojem se objavljuju originalni recenzirani naučni članci i interdisciplinarni prikazi istraživanja iz oblasti sportske nauke. Svrha časopisa je promocija nauke i istraživanja, sa posebnom pažnjom posvećenom sportskoj nauci širom Crne Gore i izvan nje. Meta-analiza daje pregled objavljenih originalnih naučnih radova iz oblasti motoričkih sposobnosti odbojkaša/ica u časopisu "Sport Mont" od 2006 do 2016. godine. Sistematski pregled pokazuje komparativnu analizu prikupljenih studija i obrađenih podataka. Može se zaključiti da je trenažni program rada kod svih naučnih orginalnih radova iz oblasti motoričkih sposobnosti odbojkaša/ica doveo je do pozitivnih transformacija. Na osnovu dobijenih rezultata iz originalnih objavljenih naučnih radova može se registrovati određeno stanje sportiste i te rezultate uporediti sa nekim prethodno utvrđenim kriterijumom. Naime, dobijeni rezultati mogu biti usmjereni u pravcu inoviranja planova i programa rada, te prilagođavanju potrebama dotične populacije. Pored dijagnostikovanja, planiranja i programiranja trenažnog procesa, rezultati se mogu primijeniti i u svrhu individualnog praćenja sportista i unošenja korekcije u metode obučavanja, utvrđivanja i unapređivanja razlika sposobnosti kod sportista različitog sporskog usmjerenja.

\section{Acknowledgements}

There are no acknowledgements.

Conflict of Interest

The authors declare that there are no conflicts of interest. 
Received: 1 August 2018 | Accepted: 29 August 2018 | Published: 29 October 2018

\section{References}

Batez, M. (2013). Razlike u motoričkom status djece različitog pola u školi odbojke. Sport Mont, 12(37-38-39), 351-5.

Bećir, Š. (2006). Prediktorske vrijednosti bazično-motoričkih sposobnosti i relacije sa situaciono-motoričkim informacijama u odbojci kod 15-to godišnjaka. Sport Mont, 4(10-11), 375-80.

Bjelica, D., Popović, S., \& Gardašević, J. (2016b). Opći principi planiranja programiranja fizičkih priprema sportaša. Zbornik radova 14.godišnje međunarodne konferencije "Kondicijska priprema sportaša" (190-192), Zagreb: Udruga kondicijskih trenera Hrvatske.

Bukvić, O., Huskić, S., \& Aruković, Z. (2008). Faktorska struktura situaciono-motoričkih varijabli odbojkaša-početnika. Sport Mont, 6(15-16-17), 877-82.
Karadžić,P., Doder, D., \& Dokmanac, M. (2011). Razlike u motoričkim sposobnostima odbojkaša i netreniranih učenika. Sport Mont, 9(31-32-33), 1104.

Korjenić, A., \& Jelčić, M. (2011). Transformacioni efekti bazično-motoričkih sposobnosti pod uticajem eksperimentalnog programa rada kod odbojkaša 16-18 godina. Sport Mont, 9(31-32-33), 572-9.

Kunstlinger, U., Ludwig, H.G., \& Stegemann, J. (1987). Metabolic changes during volleyball matches. Internationa Journal of Sports Medicine, 8, 315-22.

Mahmutović, I., Rađo, I., Talović, M., Lakota, R., Alić, H., \& Jelešković, E. (2016). Nivo transformacije motoričkih vještina odbojkašica pod uticajem trenera. Sport Mont, 14(2), 39-43.

Marelić, N., Djurkovic, T. \& Rešetar, T. (2008). Razlike u kondicijskim sposobnostima i morfološkim karakteristikama odbojkašica različitog statusa u ekipi. Hrvatski Športskomedicinski Vjesnik, 23(1), 30-4. 